\title{
ADUBAÇÃO ORGÂNICA E MINERAL NA PRODUÇÃO DE SEMENTES DE ABOBRINHA ${ }^{1}$
}

\author{
ELAINE GONÇALVES RECH ${ }^{2}$, LUCIABRANDÃOFRANKE ${ }^{3}$, INGRID BERGMAN INCHAUSTIDEBARROS ${ }^{4}$
}

\begin{abstract}
RESUMO - Este estudo teve o objetivo de verificar os efeitos da adubação orgânica e mineral sobre os componentes do rendimento e potencial produtivo de sementes de Cucurbita pepo L. var melopepo cv. Caserta. A pesquisa foi conduzida no Centro Agrícola Demonstrativo da Prefeitura de Porto Alegre durante os anos de 2002/03. Os tratamentos consistiram em T1 = testemunha, T2 = adubação mineral e do T3 ao T6 em adubação orgânica (cama de aviário), nas doses de 63, 125, 187 e 250 g.cova ${ }^{-1}$, respectivamente. O delineamento experimental foi o de blocos casualizados com três repetições. Foram determinados número de flores.planta ${ }^{-1}$, número de frutos.planta-1 , peso $^{-1}$ médio de frutos, peso de sementes.fruto ${ }^{-1}$, número de sementes.fruto ${ }^{-1}$, peso de 1000 sementes e $^{2}$ rendimento de sementes.área ${ }^{-1}$. A aplicação de cama de aviário aumentou o rendimento de sementes de abobrinha. A dose de cama de aviário que proporcionou maior rendimento de sementes $\left(3,12\right.$ t.ha' $\left.a^{-1}\right)$ foi de 250g.cova ${ }^{-1}$.
\end{abstract}

Termos para indexação: Cucurbita pepo, componentes do rendimento, cama de aviário.

\section{ORGANICAND MINERAL FERTILIZATION ON THE PRODUCTION OF ZUCCHINI SEEDS}

ABSTRACT - This study was performed with the objective of verifying the effects of fertilizers on field components and the productive potential of seeds of Cucurbita pepo L. var melopepo cv. Caserta. The experiment was conducted at the Centro Agrícola Demonstrativo da Prefeitura de Porto Alegre during the years 2002/03. The treatments consisted of: T1 = control, T2= mineral fertilizer and T3 to T6 four doses of chicken litter $\left(63,125,187,250 \mathrm{~g} \cdot \mathrm{pit}^{-1}\right.$, respectively). The experiments were arranged on a randomized complete block design with three replications. The numbers of flowers.plant ${ }^{-1}$, number of fruits.plant ${ }^{-1}$, mean fruits weight, seed weight. fruit ${ }^{-1}$, number of seed.fruit ${ }^{-1}$, weight of 100 seeds and seed yield.area ${ }^{-1}$ were determined. In the experiment, the use of chicken litter increased seed yield. The dose of chicken litter which gave the greatest seed yield was $\left(3.12 \mathrm{t} \cdot \mathrm{ha}^{-1}\right)$ 250g.pit $\mathrm{pi}^{-1}$.

Index terms: Cucurbita pepo, yield components, chicken litter.

\section{INTRODUÇÃO}

Para qualquer cultura de hortaliça, a adubação orgânica e/ou química é indispensável para se obter boa produtividade. O uso de fertilizantes em áreas de produção de sementes é mais comum do que em lavouras para produção de grãos ou outros materiais de consumo, mesmo assim o número de

${ }^{1}$ Submetido em 14/02/2005. Aceito para publicação em 18/11/2005. Parte da Tese de Doutorado do primeiro autor apresentada à Universidade Federal do Rio Grande do Sul;

${ }^{2}$ Eng. Agrônoma, Dra., Estrada da Boa Vista, 371- Pelotas-RS, CEP: $96085-$ 090; elainegr@hotmail.com; experimentos relacionados especificamente a este aspecto é restrito, de modo que o emprego de fertilizantes é realizado com base nos resultados obtidos para as respectivas culturas de consumo alimentar e industrial. Ainda hoje, pouco se conhece a respeito da quantidade a utilizar, principalmente com relação ao adubo orgânico, que permita a obtenção de rendimentos satisfatórios na produção e na melhoria da qualidade de sementes (Oliveira et al., 2000).

${ }^{3}$ Eng. Agrônoma, Dra., Professora Adjunto, Departamento de Plantas Forrageiras e Agrometeorologia, UFRGS, Caixa Postal 15100. CEP: 91501970, Porto Alegre-RS; lbfranke@ufrgs.br;

${ }^{4}$ Eng. Agrônoma, Dra., Professora Titular, Departamento de Horticultura, UFRGS, Caixa Postal 15100. CEP: 91501-970, Porto Alegre-RS; ingridb@ufrgs.br. 
O emprego de fórmulas equilibradas contendo fósforo (atuante na floração, frutificação e formação de sementes, bem como promove o enraizamento das plantas) e potássio (indispensável à perfeita estruturação celular das plantas, permite aumentar sua capacidade de resistência à falta de água e às pragas e doenças), aliado à aplicação de nitrogênio (responsável pela brotação e formação da estrutura de folhas e caules) em tempo certo, estimula a produção de sementes. Uma adubação balanceada é imprescindível nos campos de produção de sementes, por influenciar a produção e a qualidade, alterando tamanho, forma, peso e coloração, bem como, evitando algumas anomalias no desenvolvimento das plântulas, manifestações mais comuns, decorrentes das deficiências de minerais (Delouche, 1981).

A agricultura, em geral, tem buscado formas de cultivo que apresentem menores custos de implantação, que causem menos danos possíveis ao meio ambiente, principalmente ao solo, objetivando um manejo conservacionista e que o uso de insumos, como fertilizantes e agrotóxicos, seja o menor possível (Martins, 1999). Neste contexto, as sementes assumem papel fundamental, pois para a produção orgânica, segundo a normativa 007/99 do Ministério da Agricultura, Pecuária e Abastecimento (Mapa) de maio de 1999, são vetados o uso de sementes produzidas com qualquer tipo de adubo químico, inseticidas químicos, agrotóxicos e outros insumos artificiais ou tóxicos, organismos geneticamente modificados (OGM)/transgênicos ou radiações ionizantes em qualquer fase do processo de produção, armazenamento e de consumo. Assim, a agricultura orgânica vem sendo apontada como opção para a agricultura familiar e tem alcançado incrementos de produção de até $25 \%$ ao ano. O cultivo de hortaliças com adubos orgânicos tem aumentado nos últimos anos, devido aos elevados custos com adubos minerais e aos efeitos benéficos da matéria orgânica em solos intensamente cultivados. As altas produtividades obtidas com o uso intensivo de fertilizantes inorgânicos e de agrotóxicos, além dos altos custos, têm sido questionadas não só por suas contradições econômicas e ecológicas, mas também por desprezar aspectos qualitativos importantes da produção vegetal (Santos et al., 1994).

Algumas espécies do gênero Cucurbita vêm sendo cultivadas em todo território brasileiro desde antes de sua colonização. No Rio Grande do Sul, a espécie Cucurbita pepo L. tem-se destacado pelas tradições culinárias, herança de imigrantes alemães e italianos (Silva, 1994). Entretanto, devido a carência de informações quanto ao fator adubação orgânica para a cultura da abobrinha, no que se refere aos componentes do rendimento e a fim de buscar subsídios para uma dosagem mais adequada de adubação orgânica para a produção de sementes de Cucurbita pepo L. var. melopepo cv. Caserta, o presente trabalho foi conduzido com o objetivo de avaliar o efeito da adubação orgânica e mineral nos componentes do rendimento e produção de sementes de abobrinha.

\section{MATERIAL E MÉTODOS}

No Centro Agrícola Demonstrativo da Prefeitura de Porto Alegre (CAD/PMPA-Viamão/RS) entre setembro de 2002 e janeiro de 2003, foi conduzido o experimento em campo. Foram estabelecidos seis tratamentos, constituídos de $\mathbf{T 1}=$ testemunha, sem adubação; T2 = adubação mineral, utilizandose a fórmula 5-20-20, sendo aplicadas $22 \mathrm{~g} \cdot \operatorname{cova}^{-1}+3 \mathrm{~g}$ de uréia.cova $^{-1}$ em cobertura 30 dias após plantio; $\mathbf{T 3}=63 \mathrm{~g} \cdot$ cova $^{-}$ ${ }^{1}$ de cama aviário, correspondendo a meia dose da recomendação da ROLAS (1994); T4 = 125g. $\operatorname{cova}^{-1}$ de cama de aviário, correspondendo à dose da recomendação da ROLAS (1994); T5 = 187g. cova $^{-1}$ de cama de aviário, correspondendo a 1,5 doses da recomendação da ROLAS (1994); T6 = 250g.cova ${ }^{-1}$ de cama de aviário, correspondendo a 2 doses da recomendação da ROLAS (1994), em área de $234 \mathrm{~m}^{2}$, subdividida em três blocos casualizados, de 26x3m, com parcelas divididas, onde cada bloco continha três linhas, cada linha contendo 30 plantas e cada tratamento constituído de quinze plantas. $\mathrm{O}$ espaçamento utilizado foi de $1 \mathrm{~m}$ entre linhas e $0,80 \mathrm{~m}$ entre plantas, com adubação efetuada na cova no momento do transplantio das mudas. Para o preparo da área fez-se uma lavração nas linhas a uma profundidade de $0,30 \mathrm{~m}$, sendo os canteiros cobertos com filme plástico preto (para cobertura 'mulching')

O solo da área é um Argissolo Vermelho eutrófico típico com textura média, profundo, relevo ondulado e substrato granito (Streck et al., 2002), apresentando as seguintes características no horizonte superficial: argila $=16 \% ; \mathrm{pH}=$ 6,8; índice SMP $=69 ; \mathrm{P}\left(\mathrm{cmol} \cdot \mathrm{L}^{-1}\right)=1100 ; \mathrm{K}\left(\mathrm{cmol} \cdot \mathrm{L}^{-1}\right)=$ 159; Matéria orgânica $=3,6 \% ; \mathrm{Ca}\left(\mathrm{cmol} \cdot \mathrm{L}^{-1}\right)=77$; $\operatorname{Mg}\left(\mathrm{cmol} \cdot \mathrm{L}^{-1}\right)=1,5$ e CTC $\left(\mathrm{cmol} \cdot \mathrm{L}^{-1}\right)=10,6$.

A adubação mineral recomendada para a cultura, segundo ROLAS (1994), foi a seguinte: $\mathrm{N}=20, \mathrm{P}=80$ e $\mathrm{K}=60$, sendo aplicado o equivalente a $400 \mathrm{~kg} \cdot \mathrm{ha}^{-1}$ da fórmula (5-2020), ou seja, 22g.cova ${ }^{-1}$ na base. A adubação nitrogenada foi feita aplicando-se $3 \mathrm{~g} \cdot \mathrm{cova}^{-1}$ de uréia em cobertura.

Para o cálculo da adubação orgânica, utilizou-se a fórmula para adubos sólidos (ROLAS, 1994): XN=A x B/100 x C/100 $\mathrm{x} \mathrm{D}$, onde $\mathrm{X}=$ quantidade do nutriente em $\mathrm{kg} \cdot \mathrm{ha}^{-1}$ (necessidade 
da cultura); $\mathrm{A}=$ quantidade do adubo a aplicar; $\mathrm{B}=$ teor de matéria seca do adubo; $\mathrm{C}=$ concentração do nutriente na matéria seca; $\mathrm{D}=$ índice de eficiência de liberação da forma orgânica para mineral

Para a produção das mudas, sementes de C. pepo var. melopepo cv. Caserta, oriundas da Empresa HORTEC (Bagé$\mathrm{RS}$ ) foram colocadas em bandejas de poliestireno expandido, com 200 células de $5 \mathrm{~cm}$ de profundidade. Em cada célula foi colocada uma semente a $1 \mathrm{~cm}$ de profundidade, utilizando-se o substrato Terra Fértil. As mudas foram levadas ao campo quando apresentavam a segunda folha definitiva.

A colheita dos frutos foi realizada entre dezembro e janeiro, quando os frutos apresentavam sinais visuais de maturação, identificados pela mudança de coloração do pedúnculo. Após a colheita, os frutos foram imediatamente levados ao laboratório e colocados em condição ambiente. Depois de pesados, foram acondicionados em refrigerador a $5^{\circ} \mathrm{C}$.

A extração das sementes foi manual, sendo os frutos cortados ao longo de seu maior eixo. Para a retirada de mucilagem que envolve as sementes fez-se a lavagem dos mesmos com água destilada. A secagem das sementes foi realizada em secador de ar forçado, a $30^{\circ} \mathrm{C}$, até as mesmas atingirem $8 \%$ de umidade, o que levou aproximadamente sete dias. A umidade das sementes foi determinada pelo método da estufa, a $105 \pm 3{ }^{\circ} \mathrm{C} / 24$ horas, utilizando duas amostras por tratamento, conforme as Regras para Análise de Sementes (Brasil, 1992).

Determinou-se os seguintes componentes do rendimento: número de flores.planta ${ }^{-1}$, número de frutos.planta ${ }^{-1}$, peso médio do fruto, peso de sementes.fruto-1, número de sementes.fruto $^{-1}$, peso de mil sementes e rendimento de sementes.área ${ }^{-1}$.

Durante o ciclo da cultura foi determinado o número de flores.planta ${ }^{-1}$, por meio de amostragens quinzenais, sendo cada amostra constituída das cinco plantas da linha central de cada tratamento. Para a determinação do número de frutos.planta ${ }^{-1}$, foram computados todos os frutos produzidos por planta de cada tratamento.

Para a determinação do número de sementes.fruto ${ }^{-1}$, foram contados o número total de sementes de cada fruto produzido nas cinco plantas da linha central de cada tratamento, calculando-se a média. As sementes foram também pesadas para se obter o peso de sementes.fruto ${ }^{-1}$.

$O$ peso de mil sementes foi obtido de acordo com as Regras para Análise de Sementes - RAS (Brasil, 1992), com oito repetições de 100 sementes obtidas da porção sementes puras.

$\mathrm{O}$ rendimento de sementes.área ${ }^{-1}$ foi determinado pelo cálculo dos componentes do rendimento da seguinte forma: Número de frutos.planta ${ }^{-1} \mathrm{x}$ número de sementes.fruto ${ }^{-1}=$ número de sementes.planta-1 ${ }^{-1}$ Número de sementes.planta $^{-1} \mathrm{x}$ peso de mil sementes $=$ Peso de sementes.planta ${ }^{-1}$; Peso de sementes.planta ${ }^{-1}$ x número de plantas.ha ${ }^{-1}(12.500)=$ Rendimento de sementes.ha-1.

Os dados obtidos foram submetidos a análise de variância e as médias comparadas pelo teste de Duncan a 5\% de probabilidade. A análise de regressão e teste $\mathrm{F}$ para contrastes para avaliação dos tipos de adubação foram realizados com o auxílio do Sistema de Análise Estatística para Microcomputadores - SANEST (Zonta e Machado, 1986). Para fins de análise estatística, o número de flores.planta ${ }^{-1}$, número de frutos.planta ${ }^{-1}$ e o número de sementes.fruto ${ }^{-1}$ sofreram transformação para $\sqrt{\mathrm{x}+1}$, mas os resultados foram apresentados com os dados originais, para melhor visualização e facilidade de interpretação.

\section{RESULTADOS E DISCUSSÃO}

Os componentes do rendimento e o rendimento de sementes de abobrinha, em função dos tratamentos estão apresentados na Tabela 1. Com relação aos componentes do rendimento de sementes, pode-se observar que, quando as médias foram comparadas pelo teste de Duncan a 5\%, houve diferenças significativas entre número de frutos.planta ${ }^{-1}$, peso de sementes.fruto ${ }^{-1}$ e peso de mil sementes, enquanto que o número de flores.planta ${ }^{-1}$, peso dos frutos e o número de sementes.fruto $^{-1}$ não foram afetados pela adubação. $\mathrm{O}$ rendimento de sementes.área ${ }^{-1}$ diferiu entre os tratamentos (Tabela 1).

Embora a análise de variância não tenha revelado diferenças significativas entre os seis tratamentos empregados para o componente número de flores.planta-1, a análise dos contrastes revelou a existência de diferenças significativas, sendo os tratamentos orgânicos em média superiores ao tratamento mineral e à testemunha. Diversos autores, trabalhando com outras espécies não encontraram aumento deste componente com o aumento nas doses de adubo (Chakrabarti et al., 1980; Thomazelli et al., 1992; Valle Lima et al., 2001). Em contrapartida, Milleo et al. (1999) observaram que plantas de feijão deficientemente supridas com nitrogênio produziram menos flores e conseqüentemente menos vagens e sementes por vagens.

$\mathrm{O}$ número de frutos.planta ${ }^{-1}$ foi superior nos tratamentos 
TABELA 1. Componentes do rendimento e rendimento de sementes de abobrinha (Cucurbita pepo L. var. melopepo cv. Caserta) cultivadas sob adubação orgânica e mineral, Porto Alegre, RS, 2002/2003.

\begin{tabular}{|c|c|c|c|c|c|c|}
\hline Componentes do rendimento & $\mathrm{T} 1$ & $\mathrm{~T} 2$ & $\mathrm{~T} 3$ & $\mathrm{~T} 4$ & T5 & T6 \\
\hline $\mathrm{N}^{\mathrm{o}}$ flores.planta ${ }^{-1}$ & $4,29 \mathrm{a}$ & $4,68 \mathrm{a}$ & $5,77 \mathrm{a}$ & $4,42 \mathrm{a}$ & $4,74 \mathrm{a}$ & $4,68 \mathrm{a}$ \\
\hline $\mathrm{N}^{\mathrm{o}}$ frutos.planta ${ }^{-1}$ & $1,22 \mathrm{~b}$ & $1,32 \mathrm{ab}$ & $1,33 \mathrm{ab}$ & $1,63 \mathrm{a}$ & $1,57 \mathrm{a}$ & $1,64 \mathrm{a}$ \\
\hline Peso frutos $(\mathrm{kg})$ & $1,33 \mathrm{a}$ & $1,33 \mathrm{a}$ & $1,47 \mathrm{a}$ & $1,45 \mathrm{a}$ & $1,61 \mathrm{a}$ & $1,59 \mathrm{a}$ \\
\hline Peso sem.fruto ${ }^{-1}(\mathrm{~g})$ & $23,72 \mathrm{bc}$ & $23,16 \mathrm{c}$ & $25,17 \mathrm{abc}$ & $23,90 \mathrm{bc}$ & $26,36 \mathrm{ab}$ & $27,29 \mathrm{a}$ \\
\hline $\mathrm{N}^{\mathrm{o}}$ sem.fruto ${ }^{-1}$ & $183,00 \mathrm{a}$ & $209,33 \mathrm{a}$ & $225,47 \mathrm{a}$ & $212,77 \mathrm{a}$ & $192,90 \mathrm{a}$ & $267,06 \mathrm{a}$ \\
\hline Peso mil sementes ( $g$ ) & $132,05 \mathrm{e}$ & $132,12 \mathrm{e}$ & $134,77 \mathrm{c}$ & $132,55 \mathrm{~d}$ & $152,47 \mathrm{a}$ & $139,77 \mathrm{~b}$ \\
\hline \multicolumn{2}{|c|}{ Rendimento de Sementes $\left(\mathrm{kg} \cdot \mathrm{ha}^{-1}\right) 368,51 \mathrm{f}$} & $456,25 \mathrm{e}$ & $505,12 \mathrm{c}$ & $494,12 \mathrm{~d}$ & $577,12 \mathrm{~b}$ & $765,12 \mathrm{a}$ \\
\hline
\end{tabular}

Médias seguidas de mesma letra, na linha, não diferiram, pelo teste de Duncan a 5\% de probabilidade.

$\mathrm{T} 1=$ Testemunha (sem adubação); T2 = Mineral $\left(5-20-20=22 \mathrm{~g} \cdot\right.$ cova $^{-1}=3 \mathrm{~g}$ de uréia $) ; \mathrm{T} 3=63 \mathrm{~g} \cdot$ cova $^{-1}$ de cama de aviário; $\mathrm{T}=125 \mathrm{~g}$. cova $^{-1}$ de cama de aviário; T5 $=187 \mathrm{~g} \cdot \operatorname{cova}^{-1}$ de cama de aviário; T6 $=250 \mathrm{~g}$.cova ${ }^{-1}$ de cama de aviário.

T4, T5 e T6, não diferindo de T2 e T3. A testemunha apresentou o menor número de frutos.planta ${ }^{-1}$, mas não diferiu de T2 e T3. Verifica-se que houve menor produção de frutos.planta-1 em relação ao número de flores.planta-1 ${ }^{-1}$ Observa-se, na Tabela 1 , que em média a cada quatro ou cinco flores produzidas, foi gerado em torno de 1,5 frutos.planta ${ }^{-1}$. Isto significa que nem todas as flores reverteram em frutos. Segundo Navarro Jr. (1998), trabalhando com soja, o alto potencial de produção na floração representado pela produção de grande número de flores, não necessariamente identifica uma cultivar eficiente na fixação de estruturas reprodutivas e se traduz numa produção final elevada. Quando a cultura é conduzida com o objetivo de comercializar os frutos imaturos, a colheita destes frutos e a eliminação dos frutos que já passaram do ponto de colheita estimula a formação de novos frutos. Isto ocorre, segundo Monteiro e Mexia (1988), porque entre o quinto e o décimo quinto dia após a antese, os frutos entram em fase de crescimento intenso. Esta situação caracteriza competição elevada entre os mesmos, promovendo o abortamento de parte dos frutos fixados inicialmente. Isso é explicado pela força de drenos na planta, pois frutos são drenos prioritários e a partição de assimilados entre as diferentes partes da planta mostrou ser tanto mais favorável aos frutos, quanto maior a força dos mesmos como dreno, estabelecida pelo número crescente de frutos na planta. Segundo esses mesmos autores há também redução no peso médio do fruto à medida que cresce o número de frutos por planta. Analisando-se individualmente as plantas, tal fato foi observado no presente trabalho, onde plantas que fixaram apenas um fruto, em geral, tiveram frutos maiores e plantas que fixaram mais de um fruto tiveram o tamanho do fruto reduzido.

O incremento no número de frutos por planta foi representado por uma relação linear, ou seja, houve incremento no número de frutos.planta ${ }^{-1}$ à medida que aumentaram as doses de adubo orgânico (Figura 1).

A comparação de médias não acusou diferenças significativas (Tabela 1) para todos os tratamentos empregados, no entanto, a análise de contrastes revelou a existência de diferenças significativas para peso médio dos frutos, sendo os tratamentos orgânicos em média superiores ao tratamento mineral e a testemunha. Quando foram comparadas as quatro doses de adubo orgânico com a testemunha, observou-se que o incremento de peso médio de

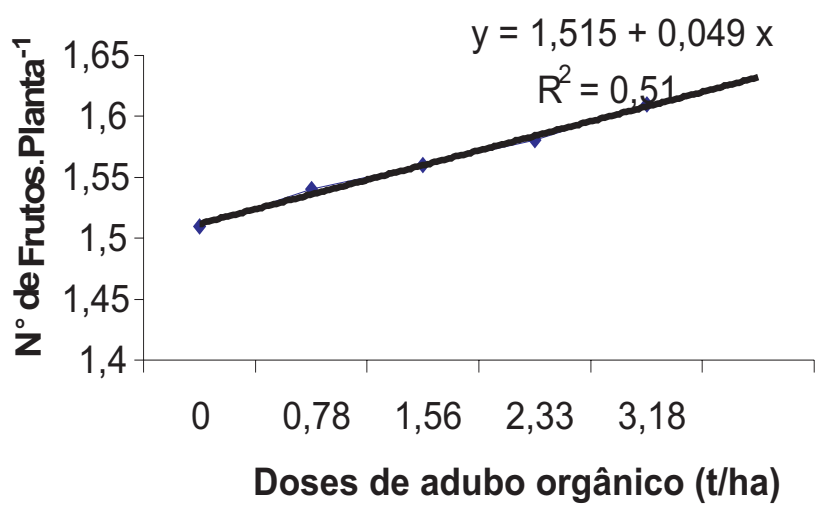

FIGURA 1. Relação entre doses de adubo orgânico e número de frutos/planta de abobrinha (Cucurbita pepo $\mathrm{L}$. var. melopepo cv. Caserta). Porto Alegre, RS, 2002/ 2003. 
frutos foi representado por uma equação linear (Figura 2). Os frutos mais pesados foram obtidos no T5 $(1,61 \mathrm{~kg})$ e os menos pesados, nos tratamentos T2 $(1,33 \mathrm{~kg})$ e $\mathrm{T} 1(1,33 \mathrm{~kg})$ conforme Tabela 1. Os valores de peso médio de frutos encontrados ficaram abaixo do encontrado por Silva (1994), que foi de $2,12 \mathrm{~kg}$ para frutos de $C$. реро var melopepo (Caserta). Essa diferença de valores, possivelmente ocorreu devido ao pequeno número de plantas utilizadas por Silva (1994), que foi de apenas oito, para avaliar essa variável.

Quanto ao peso médio de sementes.fruto-1 ${ }^{-1}$ observa-se que aquelas provenientes do T6 apresentaram maior valor, embora não tenham diferido de T5 e T3, seguido de T4 e T1. $\mathrm{O}$ tratamento de menor peso de sementes.fruto ${ }^{-1}$ foi o $\mathrm{T} 2$ (Tabela 1).

Em relação ao número de sementes. fruto $^{-1}$, observou-se que não houve diferenças significativas entre os seis tratamentos estudados. O T6 foi o que apresentou maior número delas, embora não tenha diferido dos demais (Tabela 1). No entanto Silva (1994), trabalhando com C. pepo var melopepo cultivar Caserta, encontrou média de

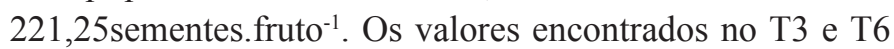
deste trabalho foram superiores aos encontrados por Silva (1994). Os demais tratamentos apresentaram valores menores. De acordo com Silva (1994), no gênero Cucurbita o número de sementes.fruto ${ }^{-1}$ pode sofrer variações, pois é influenciado (o número de frutos) pelas condições climáticas e de fertilidade do solo.

Quanto ao peso de mil sementes, os resultados mostraram que houve superioridade do T5. Os tratamentos T6, T3 e T4 foram intermediários e os de pior desempenho foram $\mathrm{T} 1 \mathrm{e}$ T2 (Tabela 1). Os dados obtidos neste trabalho para esta variável foram superiores aos encontrados por Silva (1994) com $C$. pepo L. var melopepo cultivar Caserta, que foi de $113,80 \mathrm{~g}$.

Verificou-se que o rendimento de sementes foi influenciado significativamente pelas doses de cama de aviário, crescendo linearmente com o aumento das doses, sendo a testemunha a de valor mais baixo $\left(368,51 \mathrm{~kg} \cdot \mathrm{ha}^{-1}\right)$ e o T6 o de maior valor $\left(765,12 \mathrm{~kg} \cdot \mathrm{ha}^{-1}\right)$, quando comparadas com as doses de adubo orgânico (Tabela 1 e Figura 3). Verificou-se que a maior dose de adubo orgânico proporcionou um aumento na ordem de $107 \%$ em relação ao tratamento testemunha. Este maior rendimento obtido em T6 provavelmente ocorreu em função deste tratamento apresentar maior número de sementes.fruto ${ }^{-1}$ e sementes mais pesadas. Este incremento de $107 \%$ observado no rendimento de sementes é extremamente significativo, pois a produtividade de sementes dobrou e a qualidade das sementes foi mantida. Considerandose que a semente é um insumo de alto valor agregado, o produtor alcançaria aumento significativo da lucratividade por área.

Há consenso sobre os efeitos positivos da adubação orgânica associada ou não ao adubo mineral nas hortaliças. Para a cultura de alface, Cordeiro et al. (1997) detectaram as maiores produções com aumento da adubação orgânica e da adubação mineral. No cultivo do melão, maiores produtividades foram obtidas com emprego de 20 e $30 \mathrm{~m}^{3} \cdot \mathrm{ha}^{-1}$ de composto orgânico e $50 \%$ da adubação mineral recomendada para a cultura (Rocha et al., 1998). Estudando a adubação do alho, Costa et al. (1999), obtiveram maior produção total e comercial de bulbos com esterco bovino na presença e na ausência de adubo mineral. Em couve-flor, a combinação de dose de

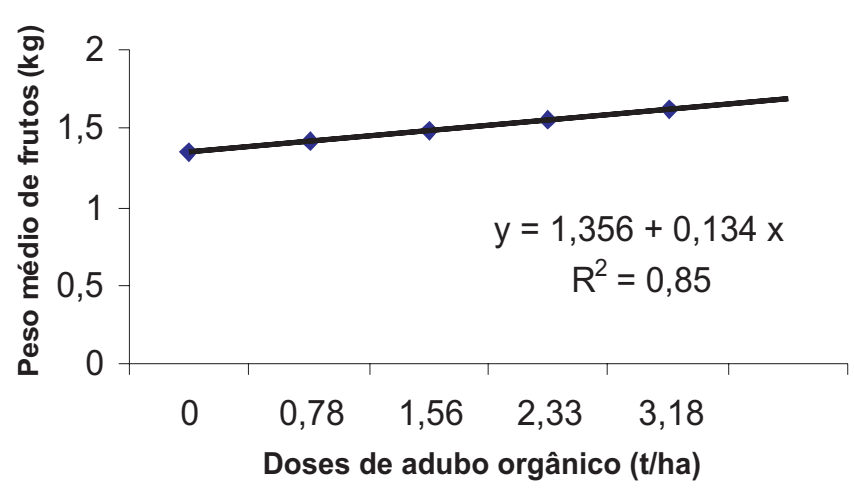

FIGURA 2. Relação entre doses de adubo orgânico e peso médio de frutos de abobrinha (Cucurbita pepo L. var. melopepo cv. Caserta). Porto Alegre, RS, 2002/2003.

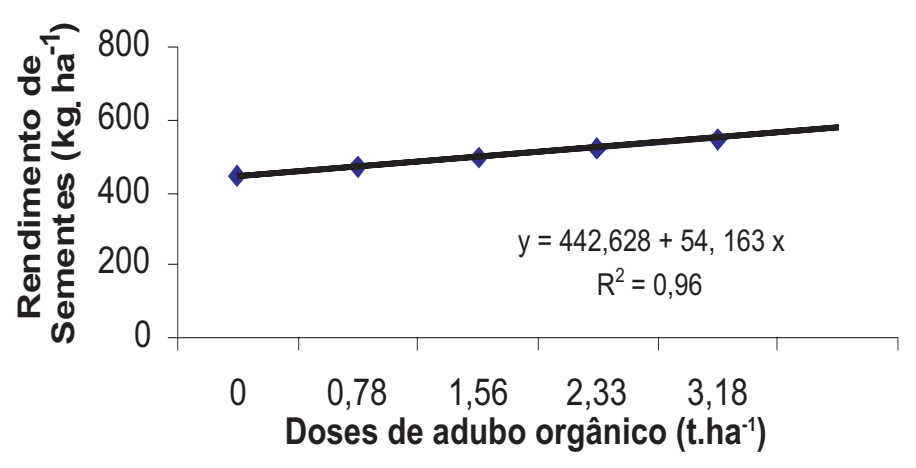

FIGURA 3. Relação entre doses de adubo orgânico e rendimento de sementes ( $t / h a ́)$ de abobrinha (Cucurbita pepo $L$. var. melopepo cv. Caserta). Porto Alegre, RS, 2002/ 2003. 
esterco e adubação mineral proporcionou aumento da produção total (Caetano et al., 1999). Resultados semelhantes também foram encontrados por Araújo et al. (2001) em feijão vagem, onde o aumento das doses de esterco suíno proporcionou aumento linear da produtividade. No entanto, a resposta do rendimento do milho em função de doses de cama de aviário foi explicada por uma equação quadrática, sendo a dose de máxima eficiência econômica estimada em 9,8t.ha ${ }^{-1}$ (Bayer et al., 1999).

Os seis tratamentos superaram a produtividade média de sementes desta espécie no Rio Grande do Sul, que situa-se em torno de 200kg.ha ${ }^{-1}$ (Secretaria de Agricultura do Estado do Rio Grande do Sul, 2003 - informação pessoal). Com base em resultados obtidos por Lopes e Casali (1982), os valores encontrados para o T1 e T2 estão dentro da faixa considerada de produção máxima para a abobrinha Caserta, em torno de $466 \mathrm{~kg} \cdot \mathrm{ha}^{-1}$. Os resultados alcançados pelos tratamentos T3, T4, T5 e T6 estão acima desta faixa. Um dos fatores que pode também ter contribuído para a grande produtividade de sementes por hectare, foi o estande de 12.500plantas. ha $^{-1}$ utilizado neste experimento, quando geralmente são utilizadas em torno de 10.000plantas.ha-1 ${ }^{-1}$.

Outro efeito positivo da aplicação das doses de cama de aviário foi, provavelmente, o balanceamento da adubação. $\mathrm{O}$ equilíbrio entre elementos nutritivos é mais importante no ganho de produtividade do que maiores quantidades de macronutrientes isolados (Primavesi, 1985).

Considerando-se que o experimento foi instalado em solo com boas condições químicas e que a análise do solo durante o ciclo da cultura mostrou que em todos os tratamentos empregados os níveis de $\mathrm{P}, \mathrm{K}, \mathrm{Ca}$ e $\mathrm{Mg}$ foram considerados altos e os teores de matéria orgânica médios (ROLAS, 1994), presume-se que os efeitos das doses de cama de aviário na produtividade de sementes de abobrinha, não se devam somente ao suprimento de nutrientes, mas também à ação melhoradora em outros constituintes da fertilidade e da estrutura do solo, como modificações nas propriedades físicas do solo, principalmente através da melhor agregação do solo, capacidade de infiltração e retenção de água, drenagem, aeração, temperatura e penetração radicular, o que não teria sido possível sem a adição de matéria orgânica (Marchesine et al., 1988; Chen e Aviad, 1990; Veranine et al., 1993).

\section{CONCLUSÕES}

A aplicação de cama de aviário aumentou o rendimento de sementes de abobrinha.
A dose de cama de aviário que proporcionou maior rendimento de sementes $\left(3,12 \mathrm{t} \cdot \mathrm{ha}^{-1}\right)$ foi de $250 \mathrm{~g} \cdot \mathrm{cova}^{-1}$.

\section{REFERÊNCIAS}

ARAÚJO, J.S.; OLIVEIRA, A.D.O.; SILVA, J.A.L.de; NETO, F.L. Rendimento do feijão-vagem cultivado com esterco suíno e adubação mineral. Revista Ceres, Viçosa, v.48, n.278, p.501-510, 2001.

BAYER, C.; CERETTA, C. A.; SCHNEIDER, N. G. Viabilidade da utilização de cama de aviário como fertilizante na cultura do milho. Revista Científica Rural, Santa Maria, v.2, p.10-14, 1999.

BRASIL. Ministério da Agricultura e Reforma Agrária. Regras para análise de sementes. Brasília: SNDA/DNDV/CLAV, 1992.365p.

CAETANO, L.C.S.; FERREIRA, J.M.; VALENTINI, L.; ANDRADE, W.E.; MANZATO, H.H.H.; RIBEIRO, L.J.; SILVA, M.F.V. Adubação orgânica e mineral em hortaliças no norte fluminense. Cultura da couve-flor. In: CONGRESSO BRASILEIRO DE OLERICULTURA, 39., Tubarão. Anais... Tubarão: SOB, 1999. p.48.

CHAKRABARTI, A.K.; CHOUCHURY, B.; SINGH, C. Effect of nitrogen and phosphorus on seed production of onion. Seed Research, New Deli, v.8, n.1, p.1-4, 1980.

CHEN, Y.; AVIAD, T. Effects of humic substances on plant growth. In: MAC CARTHY, P.; CLAPP, C.E.; MALCON, R.L.; BLOOM, P.R. (Ed.). Humic substances in soil and crop sciences: selected readings. Madison: American Society of Agronomy. Soil Science Society of America, 1990. p.161-168.

CORDEIRO, D.G.; BATISTA, E.M.; SOUSA, J. A.; MIRANDA,E. D.M. Efeito da adubação mineral e orgânica sobre a produtividade da alface (Lactuca sativa L.) cv. Marisa (AF 216), na época chuvosa, em Rio Branco- Acre. Horticultura Brasileira, Brasília, v.79, n. $15,1997$.

COSTA, C.C.; OLIVEIRA, A .P.; FERREIRA, D.S.; SILVA, A.F. Produção de alho em função de doses de esterco bovino na presença e ausência de adubo mineral. In: CONGRESSO BRASILEIRO DE OLERICULTURA, 39., 1999, Tubarão. Anais.... Tubarão: SOB, 1999. p.86.

DELOUCHE, J.C. Metodología de pesquisa em sementes. III. Vigor, envigoramento e desempenho no campo. Revista Brasileira de Sementes, Brasília, v.3, n.2, p.57-64, 1981.

LOPES, J.F.; CASALI, V.W.D. Produção de sementes de Cucurbitáceas. Informe Agropecuário, Belo Horizonte, n.8, p.6573, 1982.

MARCHESINI, A.; ALLIEVI, L.; COMOTTI, E.; FERRARIA, A. Long term effects of quality compost treatment on soil. Plant and Soil, Dordrecht, v.106, n.2, p.253-261, 1988.

MARTINS, S.R. Sustentabilidade na agricultura: dimensões econômicas, sociais e ambientais. Revista Cientifica Rural, Bagé, v.4, n.2, p.175-187, 1999.

MILLEO, M.V.R.; MONFERDINI, M.A.; ROSSI, M.S. Avaliação da eficiência agronômica de métodos para o suprimento de nitrogênio para a cultura do feijoeiro. In: REUNIÃO NACIONAL 
DA CULTURA DO FEIJÃO, 6., 1999, Salvador. Resumos Expandidos... Goiânia: Embrapa, 1999. p. 760-763.

MONTEIRO, A.A.; MEXIA, J.J. Influência da poda e do número de frutos por planta na qualidade dos frutos e produtividade do melão. Horticultura Brasileira, Brasília, v.6, n.1, p.9-12, 1988.

NAVARRO JR., H.M. Estratégias associadas a expressão do potencial de produção por planta em cultivares de soja. 1998. 82f. Dissertação (Mestrado em Fitotecnia) - Faculdade de Agronomia, Universidade Federal do Rio Grande do Sul, Porto Alegre, 1998.

OLIVEIRA, A.P.D.; ALVES, E.U.; BRUNO, R.D.L.A.; BRUNO, G.B. Produção e qualidade de sementes de feijão-caupi (Vigna unguiculata (L.) Walp.) cultivado com esterco bovino e adubo mineral. Revista Brasileira de Sementes, Brasília, v.22, n.2, p.102108, 2000.

PRIMAVESI, A. Manejo ecológico do solo: a agricultura em regiões tropicais. São Paulo: Nobel, 1985. 54 p.

ROCHA, R.C.; FARIA, C.M.B.; COSTA, N.D.; CAMPOS, C.O. Influência da adubação organo-mineral na qualidade e produtividade de frutos de melão. Horticultura Brasileira, Brasília, v.16, n.291, p. 135-140, 1998.

ROLAS. Recomendações de adubações e de calagem para os estados do Rio Grande do Sul e Santa Catarina. Passo Fundo: SBCS- Núcleo Regional Sul, 1994. 224p.

SANTOS, R.H.S.; CASALI, V.W.D.; CONDE, A.R.; MIRANDA, L.C.G. Qualidade da alface cultivada com composto orgânico.
Horticultura Brasileira, Brasília, v.12, n.1, p.29-32, 1994.

SILVA, M.A.S. Coleta e caracterização de germoplasma de Cucurbita spp. com ênfase em $C$. pepo no Rio Grande do Sul. 1994. 127f. Dissertação (Mestrado em Fitotecnia) - Faculdade de Agronomia, Universidade Federal do Rio Grande do Sul, Porto Alegre, 1994.

STRECK, E.V.; KAMPF, N.; DALMOLIN, R.S.D.; KLAMT, E.; NASCIMENTO, P.C.; SCHNEIDER, P. Solos do Rio Grande do Sul. Porto Alegre: UFRGS, 2002. 126p.

THOMAZELLI, L.F.; SILVA, R.B.D.; BIASI, B.; NOVAIS, R.F.D.; SEDIYAMA, C.S. Efeito do nitrogênio, fósforo e potássio na produção e qualidade de sementes de cebola. Revista Brasileira de Sementes, Brasília, v.14, n.2, p.161-165, 1992.

VALLE LIMA, E.D.; ARAGÃO, C.A.; MORAIS, O.M.; TANAKA, H.G.F. Adubação NK no desenvolvimento e na concentração de macronutrientes no florescimento do feijoeiro. Scientia Agrícola, Piracicaba, v.58, n.1, p.125-129, 2001.

VERANINE, Z.; PINTON, R.; BIASE, M.G.; ASTOLFI, S.; MAGGIONI, A. Low molecular weight humic substances stimulate H-ATPase activity of plasma membrane vesicles isolated from oat (Avena sativa L.) roots. Plant and Soil, Dordrecht, v.153, p.6169, 1993.

ZONTA, E.P.; MACHADO, A.A. Sistema de análise estatística para microcomputadores, SANEST. Pelotas: UFPel, Instituto de Física e Matemática, 1986. 150p. 